\title{
Evidências de Validade de um Inventário de Competências Empreendedoras para Empresários Juniores
}

\author{
Yasmin Makhamid Makhamed - Universidade Federal do Rio Grande do Norte, Natal, Brasil \\ Pedro F. Bendassolli - Universidade Federal do Rio Grande do Norte, Natal, Brasil
}

\begin{abstract}
Resumo
O objetivo do estudo foi verificar evidências de validade de um inventário de competências empreendedoras para empresários juniores no contexto brasileiro. Foram participantes 796 empresários juniores que responderam um survey online contendo o inventário de competências empreendedoras do Man e Lau, previamente adaptado para o português de Portugal e readaptado para o português brasileiro neste estudo. Foram realizadas análises fatoriais exploratórias (AFE) e confirmatórias (AFC) com duas subamostras de 398 participantes. A partir da AFE, encontrou-se uma solução de cinco fatores, que explicou $75 \%$ da variância e apresentou excelente consistência interna. Tal estrutura apresentou índices de ajustamento adequados na AFC $(\chi 2 / \mathrm{gl}=2,58, p<0,001 ; \mathrm{SRMR}=0,040 ; \mathrm{CFI}=0,93 \mathrm{e} \mathrm{TLI}=0,93)$. Os alfas de Cronbach variaram de 0,86 a 0,97. Esses resultados indicam evidências de validade do inventário como medida de competências empreendedoras em um contexto de formação empresarial.
\end{abstract}

Palavras-chave: empreendedorismo, competências, análise fatorial

Validity evidences for an entrepreneurial competences inventory to junior entrepreneurs

\begin{abstract}
This paper was designed to verify evidences of validity for an entrepreneurial competences inventory for junior entrepreneurs in Brazil. Participants included 796 junior entrepreneurs. They answered an online questionnaire, containing the inventory of entrepreneurial competences of Man and Lau, which was previously adapted into Portuguese from Portugal and readapted into Brazilian Portuguese in this study. Exploratory (EFA) and confirmatory factor analyses (CFA) were carried out with two subsamples of 398 participants. EFA indicated a five-factor structure, explaining $75 \%$ of the variance. Such a structure also presented satisfactory goodness-of-fit indexes in the $\mathrm{CFA}(\chi 2 / \mathrm{gl}=2.58, \mathrm{p}<.001$; SRMR $=.040$; $\mathrm{CFI}=.93$; and TLI $=.93)$. The internal consistency of the factors (Cronbach's alpha) ranged from .86 to .97 . These findings suggest that the inventory presents evidences of validity for use in measuring entrepreneurial competences in an entrepreneurial training context. Keywords: entrepreneurship; competences; factor analysis
\end{abstract}

\section{Evidencias de validez de un inventario de competencias emprendedoras para empresarios junior}

\begin{abstract}
Resumen
El objetivo del estudio fue verificar evidencias de validez de un inventario de competencias empresariales para jóvenes emprendedores en el contexto brasileño; 796 empresarios jóvenes contestaron una encuesta online del inventario de competencias emprendedoras del Man y Lau, adaptado previamente para el portugués de Portugal y readaptado al portugués de Brasil en este estudio. Se realizaron análisis factoriales exploratorios (AFE) y confirmatorios (AFC) con dos sub-muestras de 398 participantes. Desde la AFE fue encontrada una solución de cinco factores, que explicó $75 \%$ de la varianza y presentó excelente consistencia interna. Tal estructura presentó índices de ajuste adecuados en la $\mathrm{AFC}(\chi 2 / \mathrm{gl}=2,58, \mathrm{p}<0,001 ; \mathrm{SRMR}=0,040$; $\mathrm{CFI}=0,93$ y TLI $=0,93)$. Los alfas de Cronbach variaron de 0,86 a 0,97 . Esos resultados indican evidencias de validez del inventario como medida de las competencias emprendedoras en el contexto de formación empresarial.

Palabras-clave: emprendedorismo; competencias; análisis factorial
\end{abstract}

A problemática deste artigo relaciona-se à questão do desenvolvimento de competências empreendedoras em empresas juniores no Brasil. Empresa júnior é uma associação civil, sem fins lucrativos, com objetivos educacionais, constituída e gerida exclusivamente por alunos de graduação. Sua história remonta à França dos anos de 1960, chegando ao Brasil apenas na década de 1980. A primeira federação estadual foi criada em 1990, no estado de São Paulo (Brasil Júnior, 2012). Atualmente, o Brasil é um dos países com o maior volume de alunos de graduação vinculados a empresas juniores, com uma estimativa de 27.000 membros, distribuídos em 1.120 empresas, pertencentes a 14 federações (13 estados e o DF) (Brasil Júnior, 2010).

Em sua essência, as empresas juniores visam a três grandes objetivos: o desenvolvimento profissional de seus membros, a partir da realização de projetos na área de atuação dos cursos a que estão vinculados; a realização de serviços para micro e pequenas empresas e de terceiro setor, favorecendo o desenvolvimento local; e o fomento ao empreendedorismo (Brasil Júnior, 2007). Portanto, essas empresas consistem em espaços para o 
desenvolvimento e o aprimoramento de competências voltadas para a formação, atuando como dispositivo coadjuvante na preparação do aluno para a atuação no mercado de trabalho.

Não por acaso, os processos de aprendizagem e de desenvolvimento de competências são as temáticas mais estudadas na literatura nacional sobre empresas juniores (e.g., Campos, 2012; Campos, Abbad, Ferreira, \& Negreiros, 2014; Cesconetto, Nunes, \& Moretto Neto, 2012; Lautenschlager, 2009; Lima \& Cantarolli, 2010; Zaccarelli, 2011; Ziliotto \& Berti, 2012). Adicionalmente, mais da metade dos participantes do último Censo e Identidade realizado pela Brasil Júnior (representante nacional) percebe que a empresa júnior da qual fazem parte incentiva totalmente $(56 \%)$ ou parcialmente (35\%) o empreendedorismo (Brasil Júnior, 2014).

O estudo do empreendedorismo remete a uma longa tradição de investigações desenvolvidas em diversos campos do saber, as quais geraram uma ampla diversidade de definições. Por exemplo, Schumpeter (1982), pioneiro no estudo do tema, define o empreendedor como aquele que reconfigura (ou "destrói") a ordem econômica pela introdução de novos produtos e serviços. O empreendedorismo é também definido pela busca, criação e identificação de oportunidades (Dornelas, 2005; Shane \& Venkataraman, 2000), inovação (Henderson, 2002; Schumpeter, 1982), bem como pela abertura de novo negócio (Gartner, 1989). Esta última acepção é também utilizada pelo Global Entrepreneurship Monitor (GEM, 2010), segundo o qual o empreendedorismo seria “(...) qualquer tentativa de criação de um novo negócio ou novo empreendimento por um indivíduo, grupos de indivíduos ou por empresas já estabelecidas" (p. 215).

Porém, do ponto de vista psicológico, o que leva uma pessoa a ser empreendedora? Quais elementos psicológicos estão na base dos comportamentos ou desempenho dos empreendedores? De fato, tais questões têm sido temas recorrentes para os interessados pela Psicologia do Empreendedor (Frese \& Gielnik, 2014). Dentro dessa área, alguns pesquisadores têm desenvolvido um corpo de conhecimentos que apontam, por exemplo, para questões de personalidade (Brandstatter, 2011; Zhao, Seibert, \& Lumpkin, 2010), propensão a assumir riscos (Stewart \& Roth, 2001), motivação (Carsrud \& Brännback, 2011), entre outras dimensões ou variáveis psicológicas. Existe, ainda, outra linha de investigações que busca compreender quais seriam as competências necessárias ao empreendedor e o modo de promovê-las. É nesse ponto que a literatura sobre empreendedorismo cruza com a literatura sobre competências, um ramo importante no campo da Psicologia do Trabalho e das Organizações (e.g., Ahmad, Halim, \& Zainal, 2010; Mitchelmore \& Rowley, 2010; Zampier \& Takahashi, 2014).

$\mathrm{Na}$ literatura, há duas grandes perspectivas de estudo sobre competências: a americana, com o foco nas características do indivíduo; e a francesa, que realça a importância da ação na definição de competência. A primeira tem como precursores McClelland (1973) e Boyatzis (1982), autores que definem competências como um conjunto de capacidades humanas que abrangem os conhecimentos, as habilidades e as atitudes (CHA) (Fleury \& Fleury, 2001). Já a perspectiva francesa associa as competências às realizações concretas do indivíduo, à sua capacidade de mobilizar conhecimentos para dar conta de demandas concretas de ação (Le Boterf, 2003; Zarifian, 2001). Mais recentemente, pode-se encontrar esforços de integração entre essas duas grandes perspectivas, propondo as competências como um conjunto de características pessoais expressas em um contexto de trabalho, traduzidas em desempenho (e.g., Brandão \& Borges-Andrade, 2007). Tais perspectivas e definições levaram, ao longo das décadas, à construção de diversos modelos e taxionomias de competências, estudadas e avaliadas nos mais amplos contextos e situações, como no caso do empreendedorismo.

Portanto, competências empreendedoras referem-se ao conjunto de conhecimentos, habilidades, atitudes e sua respectiva mobilização prática, de modo a sustentar o desempenho empreendedor (Bird, 1988; Man, 2001). Inicialmente, elas foram identificadas no contexto das competências gerenciais, tendo em vista a premissa de que empreendedores têm, entre suas principais atribuições, a função de gerenciar a empresa fundada por eles próprios (Man, 2001). Com o tempo, porém, há o desenvolvimento de taxionomias mais amplas, incorporando definições igualmente mais amplas sobre empreendedorismo, as quais vão além do simples fato de gerenciar um negócio. Nesse contexto, merece destaque o modelo de competências empreendedoras desenvolvido por Man e Lau (2000), base do presente artigo.

Embora utilizando uma abordagem comportamental, dinâmica e processual de competências (portanto, mais próxima da perspectiva francesa discutida acima), Man e Lau (2000) assumem que também é necessária a posse de conhecimentos, habilidades e atitudes para o alcance do desempenho empreendedor. 
Assim, esses autores desenvolvem um modelo que visa a identificar a presença de competências no comportamento/ação manifestadas pelo empreendedor.

Para tanto, propõem uma taxonomia de seis dimensões de competências, as quais se referem às tarefas ou às demandas centrais do desempenho empreendedor, a saber: 1) competências de oportunidade, concernentes ao reconhecimento de oportunidades de novos negócios/mercados; 2) competências de organização, relacionadas à organização de diferentes recursos internos e externos: humanos, físicos, financeiros e tecnológicos; 3) competências de relacionamento, referentes às interações baseadas nos relacionamentos entre indivíduos; 4) competências estratégicas, associadas a escolha, avaliação e implementação das estratégias na empresa; 5) competências de comprometimento, aquelas que levam o empreendedor a seguir em frente com o negócio; e 6) competências conceituais, relacionadas a diferentes habilidades conceituais que estão refletidas no comportamento do empreendedor (Man \& Lau, 2000).

Esse modelo taxionômico influenciou, do ponto de vista teórico, diversos estudos sobre competências empreendedoras realizados no Brasil (e.g., Honma \& Teixeira, 2011; Zampier \& Takahashi, 2014). Alguns desses se propõem a agregar novas dimensões ao modelo, como é o caso do trabalho de Mello, Fonsêca e Júnior (2007). Porém, embora se inspirando no modelo de Man e Lau (2000), grande parte desses estudos desenvolve seus próprios instrumentos ou opta por desenhos qualitativos. Desse modo, até o presente, não se identifica a utilização do instrumento desenvolvido com base nesse modelo taxonômico.

De fato, fundamentado em pesquisas exploratórias com empreendedores de Hong Kong, Man (2001) desenvolveu e validou um instrumento de 53 itens, baseados nas dimensões iniciais do modelo de Man e Lau (2000). Nele, cada respondente é solicitado a fazer uma autoavaliação sobre o quanto julga ser capaz de expressar cada um dos comportamentos listados em sua rotina de trabalho como empreendedor. $\mathrm{O}$ autor encontrou uma estrutura fatorial com dez fatores, com cargas fatoriais variando entre 0,33 e 0,90 .

Mais especificamente, os resultados do estudo indicaram que as competências conceituais (Man \& Lau, 2000) foram divididas em duas áreas: competências analíticas $(\alpha=0,85)$ e de inovação $(\alpha=0,87)$. Da mesma forma, competências de organização também foram separadas em duas áreas: competências operacionais $(\alpha=0,90)$ e competências humanas $(\alpha=0,94)$.
As demais dimensões permaneceram como no modelo inicial desenvolvido por Man e Lau: competências de oportunidade $(\alpha=0,78)$, competências de relacionamento $(\alpha=0,90)$, competências estratégicas $(\alpha=0,94)$ e competências de comprometimento $(\alpha=0,85)$. Por último, foram acrescidos dois fatores, previstos pelo modelo como competências complementares, a saber: competências de aprendizagem $(\alpha=0,93)$ e competências de força pessoal $(\alpha=0,92)$.

O instrumento de Man (2001) foi adaptado e validado para ser utilizado com jovens em formação em Portugal por Carvalho (2004), a partir de uma amostra de 481 estudantes universitários de áreas tecnológicas e empresariais. Esse autor encontrou uma solução de oito fatores, com cargas fatoriais variando entre 0,43 e 0,89, semelhante ao modelo original. As competências conceituais dividiram-se em duas dimensões: competências conceituais $-1(\alpha=0,63)$, referindo-se à capacidade para inovar, enfrentar os problemas e pôr em prática ideias próprias; e competências conceituais- $2(\alpha=0,72)$, relacionadas à capacidade em lidar com o risco. Da mesma forma, as competências de organização dividiram-se em competências de organização-1 $(\alpha=0,85)$, relacionadas à capacidade de controlar o funcionamento da empresa com bons resultados; e competências de organização-2 $(\alpha=0,83)$, referente à liderança e à gestão de pessoas. Os demais fatores permaneceram como no original: competências de oportunidade $(\alpha=0,81)$, de relacionamento $(\alpha=0,84)$, estratégicas $(\alpha=0,91)$ e de comprometimento $(\alpha=0,84)$.

Este artigo visa a contribuir para a ampliação de pesquisas sobre competências empreendedoras no Brasil. Em particular, busca fornecer evidências de validade do inventário desenvolvido por Man (2001) e adaptado por Carvalho (2004). Utiliza, para tanto, um conjunto de empresários juniores brasileiros. Espera-se que tal iniciativa contribua para o processo de avaliação de um dos objetivos centrais das empresas juniores: o fomento ao empreendedorismo.

\section{Método}

\section{Participantes}

Participaram 796 empresários juniores das cinco regiões brasileiras (critério de inclusão: estar participando, no momento da pesquisa, como membro de empresas juniores). Destes, $42,2 \%$ provêm da região Sudeste. As regiões Nordeste, Centro-Oeste e Sul representam, respectivamente, $24,5 \% ; 16,3 \%$ e $14,9 \%$ da amostra, sendo os estados de Minas Gerais e São 
Paulo e o Distrito Federal os de maior concentração. A região Norte apresenta a menor participação na amostra: 2,1\%. A amostra é constituída por 421 pessoas do sexo feminino (53\%), com idade média de 20,5 anos $(D P=2,2)$. Mais da metade dos participantes $(70 \%)$ declararam que estudam em uma Instituição de Ensino Superior (IES) de natureza pública federal. A área de atuação mais frequente foi a de engenharias, com $30 \%$, seguida por ciências sociais aplicadas $(21,5 \%)$ e pelas ciências humanas $(17,7 \%)$. Quanto aos cargos exercidos, $22,6 \%$ dos respondentes eram diretores; 19,3\%,gerentes/coordenadores; 17,6\%, presidentes ou vice-presidentes; $16,1 \%$, assessores/ analistas; e $12,7 \%$, consultores. Os demais participantes eram trainees, conselheiros ou membros apenas de federação ou confederação. Se somarmos os três primeiros cargos, chega-se a um total de 59,5\% dos participantes ocupando cargos de liderança nas respectivas empresas juniores.

\section{Instrumento}

O instrumento utilizado foi a versão do modelo de Man (2001) adaptada por Carvalho (2004) para ser utilizada com universitários de Portugal. Tal versão é constituída por 40 itens, que listam atividades relacionadas à abertura ou ao desenvolvimento de um negócio e que se referem a uma das seis dimensões de competências empreendedoras necessárias para a abertura do próprio negócio, definidas por Man e Lau (2000). Elas são: as competências de oportunidade (itens $1 \mathrm{a}$ 4), as competências de relacionamento (itens 5 a 10), as competências conceituais (itens 11 a 17), as competências de organização (itens 18 a 27), as competências estratégicas (itens 28 a 36) e as competências de comprometimento (itens 37 a 40).

Devido às características do público, o instrumento foi adaptado pelo autor de forma que os respondentes fizessem uma projeção dos seus comportamentos para uma possível situação de criação de um negócio. Isso era expresso apor meio da seguinte instrução no instrumento original: "Se eu fosse proprietário de uma empresa considerava ter capacidade para...”. Então, seguiam-se os itens que correspondiam, cada um, a competências empreendedoras.

Para ser utilizado nesta pesquisa, o instrumento passou por um processo de validação semântica, realizada com o auxílio de dois juízes (um especialista em Língua Portuguesa e um especialista em Psicologia). Passou ainda por um pré-teste presencial com 20 empresários juniores e pós-juniores (estudantes egressos do movimento) da cidade de (informação retirada pela revista), de diferentes cursos de graduação, com distintas experiências e tempos de atuação. A instrução do inventário foi adaptada para "Se eu fosse proprietário de uma empresa, eu me sentiria capaz de...". Também foram feitas pequenas alterações na grafia de palavras que diferiam entre oportuguês de Portugal e o do Brasil. Cada item era avaliado em uma escala Likert de 10 pontos, variando de 1 (Discordo totalmente que sou capas) a 10 (Concordo totalmente que sou capaz).

Além doinventário de competências empreendedoras, foram também inseridas questões de caracterização sociodemográfica e contextuais da amostra e solicitadas informações, como idade, gênero, região brasileira na qual reside, área de formação ou atuação, natureza da instituição de ensino superior (se pública ou privada) e o cargo exercido na empresa júnior.

\section{Procedimentos de Coleta de Dados}

Os dados foram coletados no formato de survey online. Primeiramente, os pesquisadores contataram a Confederação Brasileira de Empresas Juniores (Brasil Júnior) e as federações de cada estado, com o intuito de solicitar o engajamento na pesquisa. Em caso afirmativo, era enviado o link do questionário online para que fosse retransmitido aos membros. Em paralelo, foram também acessados, de forma direta, membros de empresas juniores, cujos contatos puderam ser obtidos em websites, mailing lists ou outras formas públicas. Com estes, utilizou-se a estratégia de "bola de neve".

Permanentemente, após os envios, os pesquisadores monitoravam as taxas de respostas, visando a garantir a presença de membros de todos os estados da federação. Embora a amostragem tenha sido realizada por conveniência - adesão livre de respondentes que se encaixavam no perfil (estar, no momento da pesquisa, vinculado a uma empresa júnior) e que desejavam responder ao questionário (conveniência). O período de coleta ocorreu entre agosto de 2014 e janeiro de 2015. O projeto de pesquisa foi aprovado pelo Comitê de Ética XXX,sob o parecer de número XXX.

\section{Procedimento de Análise de Dados}

Primeiramente, o banco de dados foi explorado a fim de se identificar e excluir missings e outliers multivariados. A identificação destes últimos baseou-se na inspeção da Distância de Mahalanobis $(p<0,01)$. O número total de entradas no survey online foi de 1.456 questionários. Após a eliminação dos questionários incompletos (490), de questionários de pós-juniores, 
ou seja, de egressos de empresas juniores (142) (portanto, não membros dessas empresas no momento da pesquisa - critério de inclusão), missings (seis) e outliers (22), chegou-se ao número de participantes apresentado anteriormente. Em seguida, a amostra foi dividida, aleatoriamente, em duas subamostras de 398 participantes, denominadas de A1 e A2, respectivamente, a fim de se proceder com uma validação cruzada. Conduziu-se uma análise fatorial exploratória (AFE) com a A1 e uma análise fatorial confirmatória (AFC) com a outra metade (A2).

$\mathrm{Na}$ AFE, os fatores foram extraídos a partir da técnica dos componentes principais e da rotação oblíqua (Promax), mesmo método utilizado por Man (2001). Tal rotação foi utilizada por partir da premissa de que os fatores podem se correlacionar. Optou-se pela retenção de fatores baseada no critério dos autovalores e da inspeção visual do screeplot. Ponderações teóricas assistiram os pesquisadores nas decisões referentes a qual estrutura reter. Foram suprimidos os coeficientes com cargas fatoriais menores que $|0,50|$. A consistência interna dos fatores foi avaliada pelo alfa de Cronbach. A estrutura selecionada nessa etapa foi, então, submetida à AFC (com a A2).

Para a realização da AFC, os parâmetros foram estimados a partir da matriz de covariância, utilizandose o método da Maximum Likelihood (ML). A assimetria e a curtose das variáveis oscilaram de $|-0,619|$ a $|-2,019|$ e de $|0,049|$ a $|2,813|$, respectivamente. Esses intervalos não caracterizam violação severa ao pressuposto da normalidade que impedissem o uso do ML, conforme critérios expostos por Marôco (2010). Os índices de ajuste utilizados foram o Standardized Root Mean Square Residual (SRMR) (valores esperados menores que 0,08), o Root Mean Square Errorof Approximation (RMSEA) (valores esperados menores que 0,05), o Comparative Fit Index (CFI), o Tucker-Lewis Index (TLI) (ambos com valores esperados maiores que 0,90$)$ e o qui-quadrado/ graus de liberdade $\left(\chi^{2 / g l}\right)$ (valores esperados menores que 3) (Hair, Anderson, Tatham, \& Black, 2005; Thompson, 2004). As análises foram realizadas com o software AMOS (v. 21).

\section{Resultados}

Começa-se apresentando os resultados da AFE com a A1; em seguida, os da AFC com a A2. A amostra revelou-se favorável à realização da análise exploratória $(\mathrm{KMO}=0,97 ; p<0,001)$. Dentre as estruturas exploradas, a com cinco fatores apresentou solução teoricamente mais coerente quando comparada a outras. Nesse processo, foram suprimidos cinco itens, pois não atingiram coeficientes maiores que $|0,50|$. Os itens excluídos pertenciam, originalmente, às dimensões relacionamento (um item), estratégica (dois itens) e compromisso (dois itens). Como se nota pela Tabela 1 , a estrutura de cinco fatores explica $75 \%$ da variância e apresenta excelentes níveis de consistência interna (alfas), variando de 0,87 a 0,97 .

O fator 1 concentrou o maior número de itens (13), explicando $58 \%$ da variância. Reúne os itens com as maiores cargas fatoriais, indicando a grande importância do fator na estrutura empírica. Tal fator congrega variáveis de três fatores do modelo original: estratégia, organização e compromisso. Todos os itens da dimensão estratégia (menos os dois excluídos) ficaram no fator, além de metade dos itens de organização (itens $18,19,20$ e 21) e os itens que sobraram da dimensão compromisso (itens 39 e 40).

O primeiro fator foi denominado de gestão estratégica, já que as variáveis relacionadas às competências estratégicas estão na mesma dimensão das variáveis relacionadas às competências de organização. Isso indica que os empresários juniores não percebem que a estratégia esteja dissociada da gestão da empresa. Os dois itens da dimensão compromisso se assemelham, em termos de redação e conteúdo, a algumas questões das outras duas dimensões, o que pode explicar a inclusão delas nesse fator ("Controlar o funcionamento da empresa" e "Definir os objetivos da empresa a longo prazo").

O fator seguinte (fator 2, denominado de "gestão de riscos") manteve os sete itens do modelo original. Explica 7\% da variância e tem como cargas fatoriais mais altas itens relacionados à capacidade do empresário júnior em lidar com o risco. $\mathrm{O}$ fator 3 agregou itens que, no modelo original de Man e Lau (2000), diziam respeito à dimensão organização. Empiricamente, porém, eles estão compondo uma dimensão à parte, com todos seus itens fazendo referência à gestão de pessoas, sendo, por esse motivo, assim denominados.

O fator 4 permaneceu com os mesmos itens do modelo original, referentes às competências de relacionamento. A diferença é a exclusão de um item ("negociar"), devido à sua baixa carga fatorial e ao fato de carregar em outras dimensões. Seria negociar uma competência ligada a relacionamento? $\mathrm{O}$ fato de haver múltiplos carregamentos concomitantes desse item em outros fatores indica que talvez não, podendo estar igualmente presente como item de competências 
Tabela 1

Estrutura Fatorial do Inventário de Competências Empreendedoras, Variância Explicada e Índices de Consistência

\begin{tabular}{|c|c|c|c|c|c|c|}
\hline & Itens & F1 & $\mathrm{F} 2$ & F3 & $\mathrm{F} 4$ & F5 \\
\hline I29 & Elaborar o planejamento estratégico da empresa. & 1,00 & & & & \\
\hline $\mathrm{I} 32$ & $\begin{array}{l}\text { Decidir de acordo com o planejamento estratégico da } \\
\text { empresa. }\end{array}$ & 0,95 & & & & \\
\hline I35 & Analisar os resultados da empresa. & 0,84 & & & & \\
\hline $\mathrm{I} 30$ & Organizar o trabalho em função dos objetivos da empresa. & 0,83 & & & & \\
\hline $\mathrm{I} 36$ & Tomar decisões estratégicas para a empresa. & 0,82 & & & & \\
\hline $\mathrm{I} 34$ & $\begin{array}{l}\text { Avaliar os progressos alcançados considerando os objetivos } \\
\text { definidos. }\end{array}$ & 0,79 & & & & \\
\hline I40 & Definir os objetivos da empresa a longo prazo. & 0,78 & & & & \\
\hline I31 & Estruturar a empresa. & 0,78 & & & & \\
\hline I19 & Fazer o planejamento dos diferentes recursos da empresa. & 0,76 & & & & \\
\hline $\mathrm{I} 21$ & Gerir os vários recursos da empresa. & 0,58 & & & & \\
\hline I39 & Controlar o funcionamento da empresa. & 0,54 & & & & \\
\hline $\mathrm{I} 18$ & Planejar as operações do negócio. & 0,53 & & & & \\
\hline $\mathrm{I} 20$ & Manter a empresa funcionando com bons resultados. & 0,52 & & & & \\
\hline $\mathrm{I} 14$ & Lidar com determinadas situações arriscadas. & & 0,94 & & & \\
\hline $\mathrm{I} 13$ & Correr riscos moderados relacionados com o trabalho. & & 0,90 & & & \\
\hline $\mathrm{I} 15$ & Enfrentar os problemas de diferentes formas. & & 0,87 & & & \\
\hline $\mathrm{I} 17$ & Enfrentar os problemas como sendo oportunidades. & & 0,86 & & & \\
\hline I16 & Explorar novas ideias para aplicar futuramente na empresa. & & 0,71 & & & \\
\hline $\mathrm{I} 12$ & Colocar em prática novas ideias na empresa. & & 0,61 & & & \\
\hline $\mathrm{I} 11$ & Aplicar na empresa as minhas próprias ideias. & & 0,53 & & & \\
\hline $\mathrm{I} 23$ & Supervisionar os subordinados. & & & 0,91 & & \\
\hline $\mathrm{I} 24$ & Liderar. & & & 0,87 & & \\
\hline $\mathrm{I} 25$ & Gerir o pessoal da empresa. & & & 0,86 & & \\
\hline $\mathrm{I} 27$ & Delegar tarefas. & & & 0,84 & & \\
\hline $\mathrm{I} 22$ & Coordenar tarefas. & & & 0,78 & & \\
\hline $\mathrm{I} 26$ & Motivar o pessoal da empresa. & & & 0,64 & & \\
\hline $\mathrm{I} 07$ & Interagir com os outros. & & & & 1,00 & \\
\hline I05 & Me relacionar facilmente com o pessoal da empresa. & & & & 0,90 & \\
\hline $\mathrm{I} 08$ & Estabelecer bons contatos pessoais. & & & & 0,85 & \\
\hline $\mathrm{I} 10$ & Comunicar de forma correta. & & & & 0,66 & \\
\hline I09 & Entender as necessidades dos outros. & & & & 0,57 & \\
\hline $\mathrm{I} 03$ & Desenvolver novos produtos e serviços. & & & & & 0,90 \\
\hline I01 & Identificar as necessidades dos clientes. & & & & & 0,84 \\
\hline $\mathrm{I} 02$ & Satisfazer de forma eficaz as necessidades dos clientes. & & & & & 0,77 \\
\hline \multirow[t]{3}{*}{$\mathrm{I} 04$} & Identificar boas oportunidades de negócio. & & & & & 0,67 \\
\hline & Variâncias explicadas (\%) & $58,6 \%$ & $6,5 \%$ & $4,2 \%$ & $3,3 \%$ & $2,6 \%$ \\
\hline & Alfas de Cronbach & 0,97 & 0,93 & 0,95 & 0,91 & 0,87 \\
\hline
\end{tabular}

Nota. Método de Extração: Análise de Componente Principal. Método de Rotação: Promax com Normalização de Kaiser. Legenda: F1 = Gestão estratégica; F2 = Gestão de riscos; F3 = Gestão de Pessoas; F4 = Relacionamento; F5 = Oportunidade. 
estratégicas e de gestão de risco. Por último, o fator 5 manteve os quatro itens do modelo original, referentes às competências de oportunidade. Ao contrário dos primeiros fatores (relacionados a atividades internas da empresa), essa dimensão está mais relacionada a atividades externas do negócio.

Essa estrutura de cinco fatores foi submetida à AFC com a segunda parte da amostra (A2). Inicialmente, ela revelou-se pouco ajustada aos dados, considerando os índices de ajustamento: $\chi 2 / \mathrm{gl}=3,278$, $p<0,001$; RMSEA $=0,080$; SRMR $=0,049$; CFI $=$ 0,894 ; e TLI $=0,885$. Visando melhorar o ajuste do modelo, procedeu-se à sua reespecificação, tomando como base as sugestões oferecidas pelo software (índices de modificação).

A primeira decisão refere-se à exclusão de dois itens (9 e 10) que carregaram em três e cinco fatores, respectivamente. Em seguida, observaram-se covariâncias entre os erros (resíduos) de cinco pares de itens, provavelmente devido a proximidades semânticas entre eles. Tomou-se a decisão de traçar uma trajetória ligando esses erros, entendendo haver suporte teórico para tanto. Referem-se às duplas e11-e12 (relativas a itens que versam sobre novas ideias e sua aplicação no negócio); e13-e14, referentes a itens cujo objetivo é avaliar a propensão do respondente a lidar com o risco; e18-e19, relativos a itens que dizem respeito ao planejamento; e34-e35, em que progresso e resultados podem ter sido percebidos como próximos entre si; e a dupla e20-e39, referentes a itens que utilizaram verbos que concernem a comportamentos similares (manter e controlar) no que diz respeito à gerenciar o funcionamento do negócio. O modelo resultante é apresentado na Figura 1.

Como resultado das modificações, foi observado um incremento nos índices de ajustamento do modelo, tornando a solução de cinco fatores suficientemente ajustada aos dados. Os índices obtidos foram: $\chi^{2 / \mathrm{gl}}=$ 2,582, $p<0,001$; RMSEA $=0,067$; SRMR $=0,040$; CFI $=0,933$; e TLI $=0,926$. Os alfas para cada um dos fatores também revelam excelente consistência interna: F1 $=0,96, \mathrm{~F} 2=0,92, \mathrm{~F} 3=0,94, \mathrm{~F} 4=0,89$ e F5 $=0,86$.

\section{Discussão}

O objetivo deste estudo consistiu em investigar as evidências de validade do inventário de competências empreendedoras elaborado por Man (2001), na versão adaptada por Carvalho (2004) e readaptada ao português do Brasil. Tal investigação foi realizada com uma amostra de empresários juniores brasileiros, já que o fomento do empreendedorismo se apresenta como um dos objetivos do Movimento Empresa Júnior, como apontado na introdução do artigo (Brasil Júnior, 2007). A análise exploratória com uma primeira porção da amostra (A1) indicou a extração de cinco fatores relativos às competências empreendedoras; já a confirmatória apontou que essa estrutura ajusta-se aos dados empíricos representados pela segunda porção da amostra (A2), em que pese a necessidade de algumas reespecificações do modelo. No que segue, foram discutidas as convergências e divergências do modelo aqui identificado e os modelos utilizados como pano de fundo - tanto o de Man original como a versão adaptada por Carvalho. A Tabela 2 sintetiza a situação.

No que diz respeito às convergências, a primeira refere-se à dimensão Organização, a qual se desdobrou em duas: na primeira, estão as atividades de planejamento e controle de recursos; na segunda, as atividades de gestão de pessoas e liderança. Isso revela que talvez seja duas características percebidas como distintas pelos respondentes, o que pode indicar a necessidade de recomposição dessa dimensão, de modo a refletir essa convergência de percepções. Ao mesmo tempo, essa perspectiva poderia ensejar uma reflexão sobre a relação entre gestão de pessoas e gestão estratégica das organizações. Não seria a primeira uma ação estratégica? Essa separação de dimensões não poderia demonstrar uma maior necessidade de discussão acerca do reconhecimento da gestão de pessoas como um aspecto inserido na gestão global do negócio?

Contudo, uma possibilidade alternativa para se entender esse resultado é considerar que os respondentes percebem as pessoas como um "recurso" diferente - e, por essa razão, justificam sua gestão de forma diferenciada. Assim, pode estar relacionado às diferentes visões sobre a área de gestão de pessoas, conforme argumentam Gondim, Souza e Peixoto (2013): de um lado, como "recursos humanos", quando se percebem as pessoas como mais um recurso que deve ser gerido junto aos recursos financeiros, materiais, tecnológicos. De outro lado, a área é vista do ângulo da "gestão de pessoas" e, nesse caso, a gestão de indivíduos e grupos é pensada em um nível distinto dos demais recursos organizacionais, uma vez que existem elementos (como a subjetividade e a política) que os diferenciariam. Isso pode ter influenciado na separação observada, em que estudantes e gestores percebem que são necessárias diferentes competências para lidar com as pessoas e para lidar com os demais recursos da organização. 


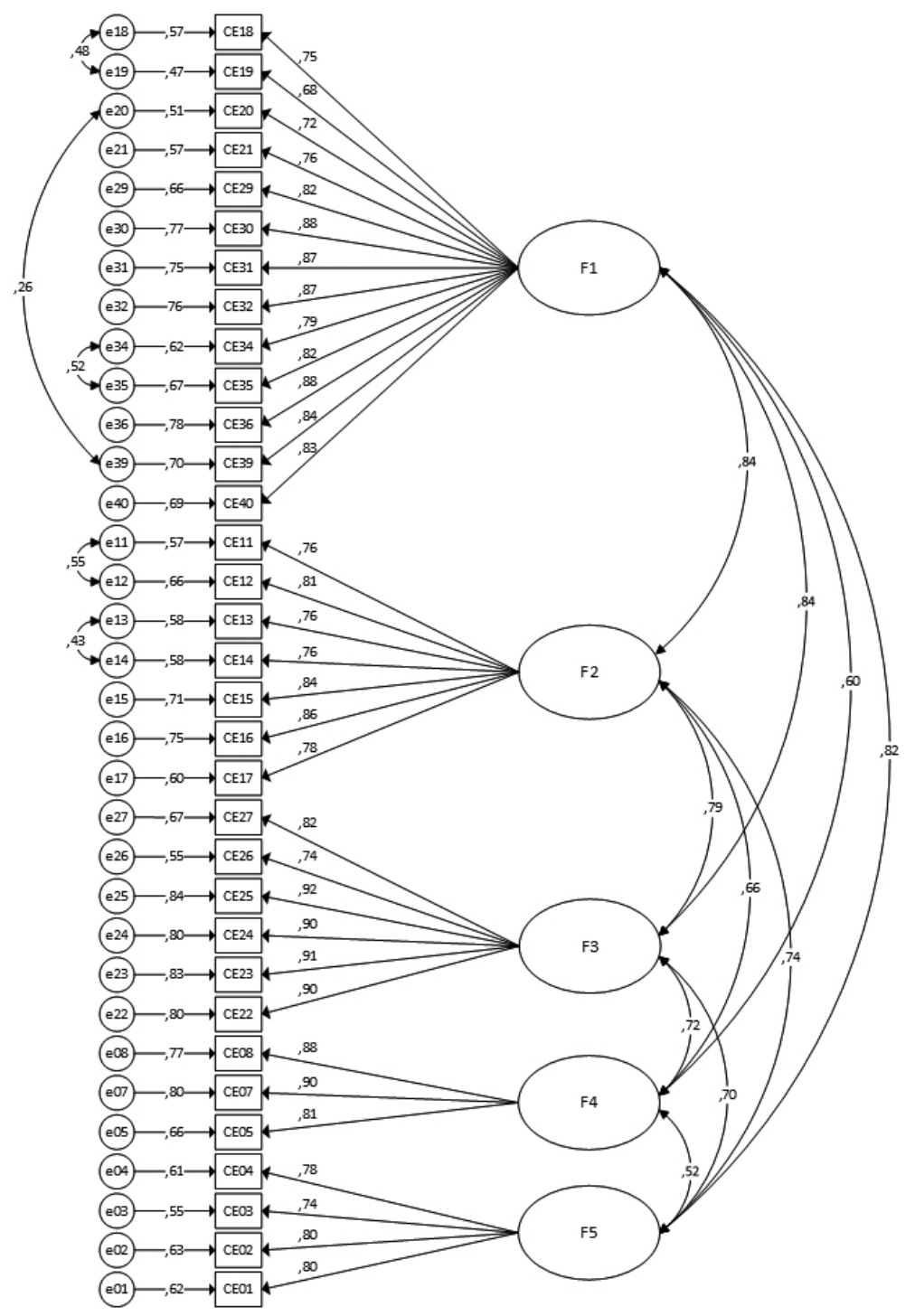

Nota. Matriz de covariância Maximum Likelihood. Legenda: F1 = Gestão estratégica; F2 = Gestão de riscos; F3 = Gestão de Pessoas; F4 = Relacionamento; F5 = Oportunidade.

Figura 1. Modelo estrutural (da AFC) com as respectivas estimativas padronizadas.

Ainda quanto às semelhanças entre os três modelos (Tabela 2), as dimensões de competências de relacionamento e as competências de oportunidade permaneceram estruturalmente semelhantes, indicando serem inerentes à concepção de empreendedorismo dos respondentes. Como consequência, são dimensões empiricamente mais estáveis no modelo teórico de Man e Lau (2000). Como apresentado na introdução deste artigo, é perceptível a importância conferida à identificação de oportunidades no empreendedorismo, sendo, inclusive, utilizado como sinônimo de empreendedorismo para algumas perspectivas (Dornelas, 2005; Shane \& Venkataraman, 2000).

O desenvolvimento de competências de relacionamento pode ser verificado também em outros estudos com empresários juniores. Campos, Abbad, Ferreira e Negreiros (2014), por exemplo, encontraram que comunicação oral e escrita efetiva e relacionamento interpessoal figuram entre as categorias mais frequentes de competências que empresários juniores desenvolvem em suas experiências. Similarmente, no estudo de Lautenschlager (2009), comunicação verbal 
Tabela 2

Comparação Entre os Resultados da AFE Encontrados Por Man (2001), Carvalho (2004) e no Presente Estudo

\begin{tabular}{|c|c|c|c|}
\hline & Man (2001) & Carvalho (2004) & Presente estudo \\
\hline Participantes & $\begin{array}{l}153 \text { empreendedores de Hong } \\
\text { Kong }\end{array}$ & 481 estudantes portugueses & $\begin{array}{l}796 \text { empresários juniores } \\
\text { brasileiros }\end{array}$ \\
\hline Itens & 53 itens & $\begin{array}{l}39 \text { itens } \\
\text { Item eliminado: } 11\end{array}$ & $\begin{array}{l}33 \text { itens } \\
\text { Itens eliminados: } 6,9,10,28 \text {, } \\
33,37,38\end{array}$ \\
\hline \multirow[t]{2}{*}{ Fatores } & $\begin{array}{l}\text { Competências conceituais e } \\
\text { competências organizacionais } \\
\text { se dividiram em dois fatores } \\
\text { cada. Foram acrescidos dois } \\
\text { fatores de competências } \\
\text { complementares. }\end{array}$ & $\begin{array}{l}\text { Competências conceituais e } \\
\text { competências organizacionais } \\
\text { se dividiram em dois fatores } \\
\text { cada. Os demais fatores } \\
\text { permaneceram como no } \\
\text { modelo original. }\end{array}$ & $\begin{array}{l}\text { Competências de organização } \\
\text { dividiram-se em dois fatores. } \\
\text { Um deles recebeu ositens de } \\
\text { competências de estratégia e de } \\
\text { comprometimento. }\end{array}$ \\
\hline & $\begin{array}{l}\text { Dez fatores. Competências: } \\
\text { analíticas, inovação, } \\
\text { operacionais, humanas, } \\
\text { oportunidade, } \\
\text { relacionamento, estratégicas, } \\
\text { comprometimento, } \\
\text { aprendizagem e força pessoal. }\end{array}$ & $\begin{array}{l}\text { Oito fatores. Competências: } \\
\text { conceituais-1, conceituais- } 2 \text {, } \\
\text { organização-1, } \\
\text { organição-2, oportunidade, } \\
\text { relacionamento, estratégicas e } \\
\text { comprometimento. }\end{array}$ & $\begin{array}{l}\text { Cinco fatores. Competências: } \\
\text { gestão estratégica, gestão } \\
\text { de riscos, gestão de } \\
\text { pessoas, relacionamento e } \\
\text { oportunidade. }\end{array}$ \\
\hline Alfas & 0,85 a 0,94 & 0,63 a 0,91 & 0,87 a 0,97 \\
\hline $\begin{array}{l}\text { Cargas } \\
\text { Fatoriais }\end{array}$ & 0,33 e 0,90 & 0,43 a 0,89 & 0,52 a 1,00 \\
\hline
\end{tabular}

e relacionamento interpessoal apareceram como as competências que os empresários juniores julgavam ter melhor desenvolvido graças à participação em empresas juniores.

Já no que diz respeito às divergências entre os modelos comparados na Tabela 2, duas em particular são destacadas. A primeira delas gira em torno da extração do fator competências de gestão estratégica, que congregou itens provenientes das dimensões de Organização e de Estratégia. Trata-se do fator com mais itens e, consequentemente, com a maior capacidade de explicação da variância. Esse resultado indica que os empresários juniores, diferentemente dos empresários de Hong Kong e dos universitários de Portugal, associam estratégia com o nível tático (o nível da organização de recursos, de planejamento, de controle de resultados e do funcionamento do negócio).

Uma possível explicação nesse sentido é de natureza contextual. Trata-se da ênfase do Movimento Empresa Junior (nacional) na importância do planejamento estratégico, com ampla influência nas empresas juniores de cada estado (Feldhaus, Pereira, \& Morais Neto, 2012). O último relatório da Brasil Junior (2014) revela que, das 427 empresas pesquisadas, a maioria (75\%) realiza algum tipo de planejamento estratégico. Outra explicação para essa especificidade na estrutura empírica encontrada junto a empresários juniores está associada à característica da amostra. Há uma predominância de participantes ocupando cargos de direção e presidência - portanto, diretamente envolvidos com as atividades de gestão e estratégia da empresa.

A segunda diferença deste estudo com relação aos de Man (2001) e Carvalho (2004) se observa no fator de competências Conceituais (neste estudo denominado de "competências de gestão de riscos"). Ele não se dividiu em dois fatores à parte, como ocorreu naqueles dois estudos. Manteve-se, portanto, como no modelo original de Man e Lau (2000), integrando competências analíticas e conceituais (inovação, aplicar ideias na prática, resolver problemas) e competências relativas ao manejo dos riscos. Itens relacionados a essa última competência (riscos) apresentaram as maiores 
cargas fatoriais dessa dimensão, revelando sua importância para a caracterização do fator, seguidos de itens referentes ao enfrentamento de problemas. É oportuno contextualizar que empresários juniores atuam em um ambiente onde coexistem pressões típicas do mundo dos negócios (correr riscos), mas também peculiaridades comuns ao ambiente acadêmico e formativo (aplicar ideias na prática, resolver problemas). Por essa razão, parece coerente que essa dimensão de competências tenha permanecido uma só.

Por fim, na AFC, dois pares de itens pertencentes ao fator competências de gestão de riscos tiveram seus erros correlacionados, respectivamente relacionados a colocar ideias em prática e ao manejo do risco. Do ponto de vista do instrumento, revela sobreposições a aperfeiçoar. Também foi um fator que, na AFC, contribuiu negativamente para o ajuste global do modelo - aspecto que aponta para a necessidade de mais aperfeiçoamentos, dada a importância da inovação (Henderson, 2002; Schumpeter, 1982) e da disposição de assumir riscos (Stewart \& Roth, 2001) como características definidoras do empreendedorismo, conforme apresentado na introdução do artigo.

Pode-se concluir que competências de identificação de oportunidade e de relacionamento são características mais universais do empreendedorismo e se aplicam também aos empresários juniores brasileiros. As demais competências encontradas especificamente neste estudo podem ser percebidas como relacionadas ao contexto das empresas juniores no Brasil, marcadamente as competências de gestão de riscos e as competências de gestão estratégica. $\mathrm{O}$ fator de gestão de riscos manteve os itens do modelo original, além disso, os itens que dizem respeito diretamente ao manejo de riscos foram os mais representativos do fator. Uma possível explicação para esse fato é que os empresários juniores brasileiros identificam a resolução de problemas e a aplicação de ideias novas também como ações que envolvem algum risco. Por outro lado, as competências de gestão estratégica foram as mais representativas nos empresários juniores brasileiros e agregaram gestão e estratégia no mesmo fator, como consequência de uma ênfase na importância do planejamento estratégico no contexto das empresas juniores brasileiras e de aliar tal planejamento às atividades de gestão da empresa júnior.

\section{Considerações Finais}

Pode-se concluir que as análises aqui realizadas apontam para adequadas evidências de validade e de confiabilidade do inventário de competências empreendedoras para ser utilizado com empresários juniores no Brasil.

Ainda foi apreendido que, apesar das peculiaridades provenientes do contexto formativo e da cultura organizacional das empresas juniores, os empresários juniores demonstram em seus comportamentos as principais competências necessárias para abrir o próprio negócio, especialmente no que diz respeito às competências que foram identificadas como mais universais. Ao mesmo tempo, os empresários juniores saem do contexto formativo e se inserem no mercado de trabalho atentos à importância da estratégia na gestão da empresa e a gerenciar os riscos e problemas, de forma a não prejudicar a manutenção e o crescimento das empresas.

Porém, destaca-se uma limitação que, embora externa à pesquisa, acabou por condicioná-la: o fato de haver uma grande escassez, no Brasil, de estudos sobre competências empreendedoras usando a metodologia confirmatória. Essa ausência restringiu as possibilidades de comparações com a estrutura empírica encontrada neste estudo, levando a tecer paralelos com estudos estrangeiros que se utilizaram do modelo inicial de Man e Lau (2000).

Como implicações da pesquisa, espera-se que o inventário aqui estudado possa despertar o interesse de outros pesquisadores envolvidos com a investigação de competências em contextos formativos. A partir da disponibilização de um instrumento com adequadas evidências de validade, pretende-se contribuir para estudos futuros que se dediquem a responder questões como: estariam as empresas juniores de fato contribuindo para o fomento ao empreendedorismo por meio do desenvolvimento de competências empreendedoras? $\mathrm{O}$ suporte que as empresas juniores oferecem está relacionado com o desenvolvimento dessas competências empreendedoras? Também é possível identificar, em pesquisas futuras, variações das competências empreendedoras de acordo com características contextuais dos empresários juniores, por exemplo: os empresários juniores com mais experiência desenvolvem mais competências empreendedoras?

Além disso, espera-se abrir possibilidades para o uso do instrumento pelos representantes do movimento empresa júnior com objetivos de autoavaliação enquanto movimento que pretende fomentar o empreendedorismo. Isso significa que, retomando uma questão que foi colocada no início deste artigo, tal inventário pode contribuir para o esforço de análise dos impactos 
da formação recebida por esses estudantes sobre o desenvolvimento de competências empreendedoras $\mathrm{e}$, indiretamente, para o próprio empreendedorismo uma missão do movimento de empresas juniores desde sua concepção, nos anos de 1960.

\section{Referências}

Ahmad, N. H., Halim, A., \& Zainal, S. R. M. (2010). Is entrepreneurial competency the silver bullet of sme success in a developing nation? Int. Bus. Manag., 4(2), 67-75. doi: 10.3923/ibm.2010.67.75

Bird, B. (1988). Implementing entrepreneurial ideas. Ac. of Man. Rev., 13(3), 442-454. Recuperado de http://www.jstor.org/stable/258091

Boyatzis, R. E. (1982). The competent management. New York: JohnWiley.

Brandão, H. P., \& Borges-Andrade, J. E. (2007). Causas e efeitos da expressão de competências no trabalho. RAM, 8(3), 32-49. Recuperado de http:// editorarevistas.mackenzie.br/index.php/RAM/ article/view/136

Brandstatter, H. (2011). Personality aspects of entrepreneurship: A look at five meta-analyses. Personal. Individ. Differ., 51(3), 222-230. doi: 10.1016/j. paid.2010.07.007

Brasil Júnior (Org.). (2007). Conceito Nacional de Empresa Júnior. Recuperado de: http://brasiljunior.org.br/ site/arquivos/download/2

Brasil Júnior (Org.). (2010). Relatório Nacional Censo e Identidade 2010.

Brasil Júnior (Org.). (2012). DNA Júnior. Recuperado de http://brasiljunior.org.br/site/arquivos/ download/34

Brasil Júnior (Org.). (2014). Relatório Nacional Censo e Identidade 2014. Recuperado de http:/ / brasiljunior. org.br $/$ download? file $=$ Censo $+\% 26+$ Identidade+2014+-+VF.pdf

Campos, E. B. D. (2012). Avaliação de necessidades de treinamento de empresários juniores brasileiros (Dissertação de mestrado). Universidade de Brasília, Brasília. Recuperado de: http://repositorio.unb. $\mathrm{br} /$ handle/10482/10547

Campos, E. B. D., Abbad, G. S., Ferreira, C. Z., \& Negreiros, J. L. X. M. (2014). Empresas juniores como espaços de apoio à formação profissional de estudantes universitários brasileiros. Rev. Psicol., Organ. Trab., 14(4), 452-463. Recuperado de http:// pesquisa.bvs.br/brasil/resource/pt/lil-735528

Carsrud, A., \& Brännback, M. (2011). Entrepreneurial motivations: What do we still need to know? Journal of Small Bus Mang., 49(1), 9-26. doi: 10.1111/j.1540-627X.2010.00312.x

Carvalho, P. M. R. (2004). Competências para o Entrepreneurship: Um modelo explicativo (Tese de doutorado). Universidade de Salamanca, Salamanca, Espanha. Recuperado de http://repositorio.ipcb.pt/ handle/10400.11/396

Cesconetto, S. M. M.; Nunes, T. S., \& Moretto Neto, L. (2012). As empresas juniores no desenvolvimento de competências gerenciais. R. de Adm. da UEG, 3(2), 118-141. Recuperado de http://www.revista. ueg.br/index.php/revista_administracao/article/ view/1099

Dornelas, J. C. A. (2005). Empreendedorismo: Transformando ideias em negócios. Rio de Janeiro: Campus.

Feldhaus, D. G., Pereira, M. F., \& Morais Neto, S. (2012). Gestão estratégica em redes: Desenvolvimento e aplicação de um modelo na Brasil Júnior. Revista de Gestão e Projetos, 3(3), 136-155. doi: 10.5585/gep. v3i3.84

Fleury, M. T. L., \& Fleury, A. (2001). Construindo o conceito de competência. RAC, Edição Especial, 5(spe), 183-196. doi: S1415-65552001000500010

Frese, M., \& Gielnik, M. M. (2014). The psychology of entrepreneurship. Annual Review of Organizational Psychology and Organizational Behavior, 1, 413-38. doi: 10.1146/annurev-orgpsych-031413-091326

Gartner, W. B. (1989). “Who is an Entrepreneur?” Is the wrong question. Entrepreneurship Theory and Practice, 13(4), 47-68. Recuperado de http://citeseerx.ist. psu.edu/viewdoc/summary?doi=10.1.1.371.5038

GEM. (2010). Empreendedorismo no Brasil 2010. Curitiba: IBQP.

Gondim, S. M. G., Souza, J. J., \& Peixoto, A. L. A. (2013). Gestão de Pessoas. Em L. O. Borges \& L. Mourão (Eds.), O trabalho e as Organizaçōes: Atuações a partir da Psicologia (pp. 343-375). Porto Alegre: Artmed.

Hair, J. F., Anderson, R. E., Tatham, R. L., \& Black, W. C. (2005). Análise multivariada de dados (5a ed.). Porto Alegre: Bookman. 
Henderson, J. (2002). Building the rural economy with high-growth entrepreneurs. Economic Review - Federal Reserve Bank of Kansas City, 87(3), 4570. Recuperado de http://citeseerx.ist.psu.edu/ viewdoc/summary?doi=10.1.1.161.5800

Honma, E. T., \& Teixeira, R. M. (2011). Competências empreendedoras em hotéis de pequeno porte. Revista Turismo Visão e Ação - Eletrônica, 13(1), 52-80. Recuperado de http://www6.univali.br/seer/index.php/rtva/article/view/1993

Lautenschlager, F. B. (2009). Percepşão dos graduandos sobre o desenvolvimento de competências em uma empresa júnior de Psicologia (Dissertação de mestrado). Universidade Federal de Santa Catarina, Florianópolis, Santa Catarina. Recuperado de https://repositorio.ufsc. $\mathrm{br} / \mathrm{xmlui} /$ handle/123456789/92411

Le Boterf, G. (2003). Desenvolvendo a competência dos profissionais. Porto Alegre: Artmed

Lima, T. F., \& Cantarolli, A. (2010). A formação e a construção de competências para a atuação do profissional de secretariado executivo. Revista de Gestão e Secretariado, 1(2), 94-122. doi: 10.7769/gesec.v1i2.17

Man, T. W. Y. (2001). Entrepreneurial competencies and the performance of small and medium enterprises in the hong kong services sector (Tese de doutorado). The Hong Kong Polytechnic University, Kowloon, Hong Kong. Recuperado de http://hdl.handle. net $/ 10397 / 3532$

Man, T. W. Y., \& Lau, T. (2000). Entrepreneurial competencies of SME owner/managers in the Hong Kong services sector. Jour. of Enter. Cult., 8(3), 235254. doi: 10.1142/S0218495800000139

Maroco, J. (2010). Análise de Equações Estruturais. Lisboa: Report Number.

McClelland, D. C. (1972). A sociedade competitiva. Rio de Janeiro: Expr. e Cultura.

Mello, S. C. B., Fonsêca, F. R. B., \& Júnior, F. G. J. (2007). Competências empreendedoras do dirigente de empresa de base tecnológica. RAM, 8(3), 50-76. Recuperado de http://editorarevistas.mackenzie. br/index.php/RAM/article/view/131
Mitchelmore, S., \& Rowley, J. (2010). Entrepreneurial competencies: A literature review and development agenda. IJEBR, 16(2), 92-111. doi: 10.1108/13552551011026995

Schumpeter, J. (1982). A teoria do desenvolvimento econômico. São Paulo: Abril Cultural.

Shane, S., \& Venkataraman, S. (2000). The promise of entrepreneurship as a field of research. Acad. Manag. Rev., 25(1), 217-226. doi: 10.2307/259271

Stewart, W. H., \& Roth, P. L. (2001). Risk propensity differences between entrepreneurs and managers. J. Appl. Psychol., 86(1), 145-53. doi: 10.1037/0021-9010.86.1.145

Thompson, B. (2004). Exploratory and confirmatory factor analysis: Understanding concepts and applications. Washington: American Psychological Association.

Zaccarelli, L. M. (2011). Narrativas de aprendizagem em uma comunidade de prática (Tese de doutorado). Universidade Presbiteriana Mackenzie, São Paulo). Recuperado de http://pergamum.mackenzie.br/ biblioteca/index.php

Zampier, M. A., \& Takahashi, A. R. W. (2014). Aprendizagem e competências empreendedoras. RGO, 6(4), 3-18. Recuperado de http://bell.unochapeco. edu.br/revistas/index.php/rgo/article/view/987

Zarifian, P. (2001). Objetivo competência: Por uma nova lógica. São Paulo: Atlas.

Zhao, H., Seibert, S. E., \& Lumpkin, G. T. (2010). The relationship of personality to entrepreneurial intentions and performance. J. Manag., 36(2), 381404.doi: 10.1177/0149206309335187

Ziliotto, D. M., \& Berti, A. R. (2012). A aprendizagem do aluno inserido em empresa júnior. Revista $C_{0}$ nexão, 8(2), 210-217. Recuperado de http://www. revistas2.uepg.br/index.php/conexao/article/ view/4554

Recebido em: 08/09/2015

Reformulado em: 15/02/2016

Aceito em: 07/03/2016 
Sobre os autores:

Yasmin Makhamid Makhamed é psicóloga e mestre em Psicologia pelo Programa de Pós-graduação em Psicologia pela Universidade Federal do Rio Grande do Norte.

E-mail:yasminmakhamid@hotmail.com

Pedro F. Bendassolli é professor do Departamento de Psicologia e do Programa de Pós-graduação em Psicologia pela Universidade Federal do Rio Grande do Norte, doutor em Psicologia Social do Trabalho pela USP e realizou estágios pós-doutorais na Université PARIS IX e no Instituto de Psicologia da UNB.

E-mail: pbendassolli@gmail.com

Contato com os autores:

Centro de Ciências Humanas, Letras e Artes, Departamento de Psicologia (Sala 602)

Av. Salgado Filho, 3000

Natal-RN, Brasil

CEP: 59078-970 
